\title{
Reparative histogenesis of skin: Reaction on the application of L-cysteine of argentum nitrate gel
}

\author{
Margarita B. Petrova", Natalya V. Pavlova, Elena A. Kharitonova, Nadezhda V. llyashenko
}

Department of Biology, Tver State Medical Academy, Tver, Russia; ${ }^{*}$ Corresponding Author: biologiatgma@mail.ru

Received 8 October 2012; revised 16 November 2012; accepted 6 December 2012

\begin{abstract}
The effect of L-cysteine of argentum nitrate gel on the wound process of experimental animals is investigated. The results show that the nanogel, being bacteriostatic, accelerates the course of inflammation phase resulting in fast cleansing of the wound surface and stimulation of the granulation tissue formation. The main cell elements of this tissue-fibroplasts are characterized by the state of functional excitation. The time of wound healing with the use of L-cysteine of argentum nitrate gel was reduced by three days, and the index of wound repair acceleration was about $20 \%$.
\end{abstract}

Keywords: L-Cysteine of Argentum Nitrate Gel; Skin; Healing Process; Wound Repair Stimulation; Fibroplasts

\section{INTRODUCTION}

The human organism possesses powerful protective mechanisms for the maintenance of intrinsic medium homeostasis. Conservation of the cutaneous covering integrity and its fast recovery after various injuries is an important component of this system. Traumatic processes are accompanied by a number of complex morphological, immunological and biochemical changes at the molecular, cellular, organ and organismic levels [1,2]. There are a large number of different methods and ways for wound healing stimulation, and the exploration of this field is still continuing because the notion of wound healing is extending with the current progress in medicine, biology and technical sciences [3-6]. A great deal of attention is devoted to the development of wound covering for the therapy of burns and radiation-thermal injuries with the aid of polyvinyl alcohol gel compositions having supramolecular structure [7]. In the present work we focus on the estimation of the effect of L-cysteine of argentum nitrate gel (synthesized at the biochemical laboratory of Tver State Medical Academy, patent RU No. 2423384) on the wound process in animal skin and mucous inju- ries.

\section{METHOD}

The study was made with 102 white male rats of the "Wistar" line (were coming from "Research Center of Biomedical Technologies of Russian Academy of Sciences", Moscow) with an average mass of $150 \mathrm{~g}$. The animals were kept on a standard diet under natural light exposure. All experimental procedures were conducted in accordance with the Rules of laboratory practice in the Russian Federation (2003) and with Principles on Good Laboratory Practice (OECD No. ENV/MC/CHEM (98)17, 1997).

Full layer skin defects having an area of $225 \mathrm{~mm}^{2}$ were inflicted under ether anaesthesia at the spinal surface of the body. Daily suspension St. Aureus strain 236 corresponding to the opacity standard No. 6 according to McFarland were inserted into the bottom of the wound. Attempts to use other microorganism were unsuccessful due to their fast death resulting in contamination of wound with goldish stafylococcus. In three days the inflammation process was formed.

The rats were divided into two series. Series I (pilot) was presented by animals having wound defects treated once per day for one week with L-cysteine of argentum nitrate gel (Ag concentration of $\left.1.28 \cdot 10^{-3} \mathrm{~mole} / \mathrm{l}\right)$. Aqueous solutions of L-cysteine with its concentration of $3 \cdot 10^{-3} \mathrm{~mol} / \mathrm{L}$ (app. $0.036 \mathrm{wt} \%$ ) were used. Chemical formula of cysteine is $\mathrm{HO}_{2} \mathrm{CCH}\left(\mathrm{NH}_{2}\right) \mathrm{CH}_{2} \mathrm{SH}$. Samples of L-cysteine (Acros company) with the content of the target product $99.99 \%$ were used. Water was bidistillated. The solutions under investigation contained $\mathrm{AgNO}_{3}$ produced by the same company with the concentration of the target product of $99.99 \%$. The addition of the Ag ions is related to the possible application of the product as a bactericide medicine [8].

In series II (control) the wounds were irrigated by distilled water with the same exposition. The efficiency of the gel composition action was estimated visually. The rate of wound healing was measured by the method of planimetry.

The biopsy material taken at the 7 th, 14 th and 21 st day 
of observation after injurious action were studied for the estimation of the regenerative proliferation phase by morphological methods. The tissue samples were fixed in $12 \%$ formalin (Panreac, Spain), the paraffin cuts with a thickness of 6 - 8 micrometers were stained with hematoxylin-eosin (Sigma, USA). Commonly accepted electron microscope techniques described elsewhere were used to examine the histological specimens at an ultrastructural level.

Statistical Analysis. To demonstrate statistically significant differences between groups of control and experimental animals, student's t-test was used with $p$ values less than 0.05 .

\section{RESULTS}

At the first day after operation the animals of both series visually looked sluggish with depressed appetite. During the next days of the experiment the condition of the rats received drug application was rapidly improved in contrast to the animals of the control series. The animals had good appetite, readily consumed the food, moved actively. The hair-coat covering was smooth, shiny, clean. The wounds were covered by thick scab.

The analysis of hystological specimens of regenerating tissues shows that the processes of suppurative inflammation proceed less agressively due to the influence of the gel. At the seventh day after operation of the animals treated with gel application the wound surface is covered by a relatively thin scab (Table 1) with mature granulation tissue underneath. Its cellular composition is presented by the cells of macrofage family and a large number of fibroblasts located among the vessels with vertical and horizontal orientation. Formation of lengthy epithelial wedge is noticed moving onto the granulation tissue; the epidermis adjacent to wound is hypertrophied.

In the control series of animals at the same time of seven-days observation the motion is lowered, the appetite is violated, feeding takes a long time, hair-coat covering is lusterless and untidy. Morphological studies have shown that the scab over the wound is thick and uneven; leukocytic bank composed mainly of neutronphilic granulocytes is pronounced underneath (Table 1).

Table 1. Parameters of different structures of wound defects seven days after operation (micrometers, $\mathrm{M} \pm \mathrm{m}$ ).

\begin{tabular}{ccccc}
\hline Series & Scab & $\begin{array}{c}\text { Leukocytic } \\
\text { bank }\end{array}$ & $\begin{array}{c}\text { Granulation } \\
\text { tissue }\end{array}$ & $\begin{array}{c}\text { Reclaim } \\
\text { extent }\end{array}$ \\
\hline $\begin{array}{c}\text { Control } \\
\text { (II) }\end{array}$ & 418.8 & 131.6 & 540.8 & 352.3 \\
& \pm 418.8 & \pm 12.9 & \pm 422 & \pm 29.3 \\
Pilot (I) & 324.9 & 106.2 & 722.2 & 623.4 \\
& $\pm 31.9^{*}$ & \pm 9.0 & $\pm 40.8^{*}$ & $\pm 46.9^{*}$ \\
\hline
\end{tabular}

Note: * difference with control data reliable with $p \leq 0.05$.
Granulation tissues begin to form, but their area is insignificant $(722.2 \pm 40.8 \mu \mathrm{m}$ against $540.8 \pm 422 \mu \mathrm{m}$ for gel treated samples). Buds presented by young newly arrived large endothelial cells are forming without clearance from the retained capillaries. Of the cell elements macrophages are prevailing, the fibroblasts are not numerous. The length of the epithelial wedge at the surface of the animal wounds is $352.3 \pm 29.3 \mu \mathrm{m}$ whish is small compared with that of the rats from the pilot series I (623.4 \pm $46.9 \mu \mathrm{m})$.

Electron microscope studies of the granulation tissue biopsy material of the rats of pilot series I have shown that the fibroblast cellular forms are dominating. Ultrastructural peculiarities are indicative of their high functional activity: vigorous development of the granular cytoplasmic reticulum, increase of the electronic density of the contents of its channels, formation of large polysomic aggregates, hypertrophy of the lamellated complex in which accumulation of granules and vesicles is observed, their fast propagation along the cytoplasm and intensive removal into the intercellular space.

By comparison, in the granulation tissue of the animals of control series II mainly immature fibroblasts with large bright core and cytoplasm almost free of organelles except for rare channels of smooth cytoplasmic reticulum and separate loose-lying ribosomes and polysomes are observed. In parallel with this population mature forms with well developed granular reticulum are met occasionally.

At the 14th day of observation the pilot group I of animals is characterized by smooth edges of the wound without hyperemia or edema. The wounds were covered by a thin dense scab of considerably reduced area (47 $\mathrm{mm}^{2}$ in contrast to $119.6 \mathrm{~mm}^{2}$ of the 7th day of observation (Figure 1)).

By morphological examination it was found that the connection between the scab and underlying tissue is not tight. The bottom of the wound is presented by mature connecting tissue with a large number of vessels and bundles of collagen fibers. Sporadic lymphocytes and macrofhage are present, however mostly mature fibroblasts are dominating. Epithelium accretion on the granular tissue and appearance of skin appendages may be noticed.

In the control series for the same time of observation the general condition of the rats improved and returned to normal. The animals became active, the hair-coat covering resumes its original luster. There were still some residual inflammatory infiltration and edema around the defect. The wounds were covered by uneven scab. Its removal opens the underlying fine-grained granulation tissue filling the whole defect with a faint leukocytic bank. Fibroblasts, macrofhages, vessels and collagen fibers are present in this tissue. Epithelial layer covers 


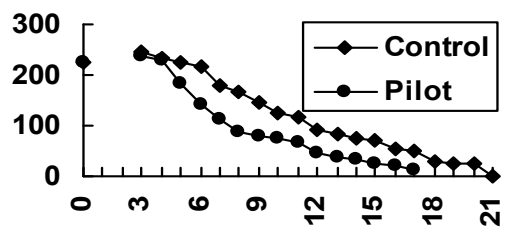

Figure 1. Wound area $\left(\mathrm{mm}^{2}\right)$ at different stages (number of days) of healing for pilot and control series of rats.

the wound edge at a considerable extent.

In the pilot series of animals (gel application) the healing of the skin defects occurs at the 18th day. Delicate scar at the place of defect was of X-type shape/ Histologically full epithelization of the wound defect and formation of skin appendage with sebaceous glands was confirmed.

In the control series the scab was still existing at the 21 st day, the inflammation effects around the wound were not noticed, the edges were smooth. A thin scab is determined in histological specimens, epithelization is nearly complete. Connective tissue contains less bundles of collagen fibers compared with the pilot series. Formation of skin appendage is mentioned.

Planimetric study shows that in the pilot series the wound area curtails much faster than in control samples. The dynamics of the process is illustrated by Figure 1. Average time of healing is shortened by 3 days with the use of the L-cysteine of argentum nitrate gel, index of wound repair acceleration was about $20 \%$.

\section{DISCUSSION}

The performed study shows that local application of the L-cysteine of argentum nitrate gel exerts a pronounced regulating impact on the wound processes in the skin. This agent facilitates the active migration of neutrofils into the wound thus impeding the penetration of pathogenic microorganisms.

Taking into account the microdosage of the solutions under study it may be concluded that in the given concentrations they possess bacteriostatic action on the pathogenic and conditionally pathogenic microorganisms [9].

The inflammation phase proceeds more energetically but at a shorter time, so the proteolytic neutrofil ferments are active only inside the wound and have no time to injure the surrounding tissues. Gel applications stimulate and activate the reparative process but do not permit its outgrow into a hyperergic reaction with injury of surrounding healthy tissues and formation of the keloid scar [10]. During the wound healing under the action of the nanogel all components taking part in the synthesis, accumulation and excretion are developed in fibroregions. We believe that this is one of the mechanisms for the realization of stimulating effect of the gel compositions under study on the regenerative processes of skin wounds.

\section{CONCLUSION}

The established peculiarities of the reactivity and regeneration of skin tissues may form a basis for further development of pharmaceutical means (drugs) and other methods of influence promoting the system-organ adaptation after injuries [11-14]. The obtained experimental data probably will be useful in the development of a medicamental form of the drug for the regulation of physiological processes during the therapy of skin defects in surgery and traumatology.

\section{REFERENCES}

[1] Abayev, Y.K. (2006) Surgeon reference book. Wounds and wound infection. Medicine, Moskow.

[2] Mehendale, F. and Martin, P. (2001) The cellular and molecular events of wound healing. Martin Dunitz, London.

[3] Nozdrin, V.I. (2006) Hystopharmacologic studies of skin. Retinoidy, Moskow.

[4] Efimenko, N.A., et al. (2002) Current Trends in producing of biologically active materials for healing of festering wounds. Voenno-Medicinsky Zhurnal, 1, 48-52.

[5] Petrova, M.B., Pustovalova R.A., Kharitonova E.A. and Pavlova N.V. (2012) Reparative process in skin. Palmarium Academic Publishing GmbH \& Co., Saarbrücken.

[6] Petrova, M.B., Shestakova, V.G., Kharitonova, E.A., Pavlova, N.V. and Kurbatova, L.A. (2012) Evaluation of acupuncture effect in skin wound healing with helping of the electronic microscope. Proceedings of the International Conference Theoretical and Practice Innovation in Science, Gdańsk, 28-30 April 2012, 14-18.

[7] Tavacalyan, N.B. and Oganesyan, A.N. (2007) Anti-burn materials on the basis of vinyl acetate polymers. Proceedings of the International Conference New Polimers and Radioprotectors for Biology and Medicine, Yerevan, 8-10 October 2007, 186-188.

[8] Ilyin, S., et al. (2011) Gels of cysteine/Ag-based dilute colloid systems and their rheological properties. Soft Matter, 7, 9090-9103. doi:10.1039/c1sm06007d

[9] Chervinets, V.M., Bondarenko, V.M., Chervinets, Y.V., Ovchinnikov, M.M., Samoukina, A.M., Mikhaylova, E.S., Petrova, M.B., Kharitonova, E.A. and Bryantseva, V.M. (2011) Antibacterial activity of nanostructured silver gel. Journal of Microbiology Epidemiology and Immunobiology, 4, 88-92.

[10] Danilov, R.K. (2008) Wounding process: Histogenetic base. Voenno-Medicinsky vestnik, Snt-Petersburg.

[11] Baum, C.L. and Arpey, C. (2005) Normal cutaneous wound healing: Clinical correlation with cellular and molecular events. Dermatologic Surgery, 31, 674-686. doi:10.1111/j.1524-4725.2005.31612

[12] Desmouliere, A. (2005) Tissue repair, contraction and the 
myofibroblast. Wound Repair and Regeneration, 13, 712.

[13] Locono, J.A. (1998) The biology of healing. In Locono J.A., Leaper, D.J. and Harding K.G., Eds., Wounds: Biology and Management, Oxford University Press, Oxford
New York, 10-22.

[14] Mast, B.A. (1992) Wound healing: Biochemical and clinical aspects: Monography. W. B. Saunders Company, London. 